\title{
BMJ Global Health The challenges of defining global health research
}

\author{
Alberto L Garcia-Basteiro (D) , ,2 Seye Abimbola (D) ${ }^{3,4}$
}

To cite: Garcia-Basteiro AL, Abimbola S. The challenges of defining global health research. BMJ Global Health 2021;6:e008169. doi:10.1136/ bmjgh-2021-008169

Received 1 December 2021 Accepted 7 December 2021

\section{Sinked}

- http://dx.doi.org/10.1136/ bmjgh-2021-005292

- http://dx.doi.org/10.1136/ bmjgh-2021-005190

Check for updates

(c) Author(s) (or their employer(s)) 2021. Re-use permitted under CC BY-NC. No commercial re-use. See rights and permissions. Published by BMJ

${ }^{1}$ Centro de Investigação em Saude de Manhiça, Manhiça, Maputo, Mozambique 2ISGlobal, Hospital Clínic Universitat de Barcelona, Barcelona, Spain

${ }^{3}$ School of Public Health, University of Sydney, Sydney, New South Wales, Australia ${ }^{4}$ Julius Global Health, Julius Center for Health Sciences and Primary Care, University Medical Center, Utrecht University, Utrecht, The Netherlands

\section{Correspondence to} Dr Alberto L Garcia-Basteiro; alberto.garcia-basteiro@ manhica.net
The term 'global health'-as a concept, a goal, a mission, a field of practice or an area of research-has been increasingly used during this 21st century. ${ }^{1}$ Global health institutes, departments, professorships, journals (such as the one hosting this editorial), masters courses and other academic programmes have emerged and continue to be created across the globe, although mostly in highincome countries.

The most widely cited definition so far is that of Koplan et al, who defined global health as 'an area for study, research and practice that places a priority on improving health and achieving equity in health for all people worldwide'. ${ }^{2}$ Koplan et al explain the differences between global health, public health and international health, terms which are understandably often used indistinctly. But since that attempt at a definition, the issue of what ought to be the most appropriate common definition of global health-and by extension, global health research- has been the subject of extensive debate..$^{3-6}$

In a recent article published in BMJ Global Health, Salm et al reported a comprehensive systematic review and thematic analysis of the definitions of global health over an 11-year period. ${ }^{7}$ They found that most definitions of global health in the articles meeting their inclusion criteria fell within one of the following four main themes: (1) a multiplex approach to worldwide health improvement taught and pursued through research institutions; (2) an ethical initiative that is guided by justice principles; (3) a form of governance that yields national, international, translational and supranational influence through political decision making, problem identification and allocation and exchange of resources across borders and (4) a polysemous concept with historical antecedents and emergent future. ${ }^{7}$

Salm et al conclude that 'global health' means many different things, and the definitions are conditioned by who makes them and the purpose and target recipients of its practice or research. They propose that global health could be defined as 'an area of research and practice committed to the application of overtly multidisciplinary, multisectoral and culturally sensitive approached for reducing health disparities that transcend national borders'. ${ }^{7}$ However, this broad definition is still, understandably, not clear-cut, particularly, when speaking about research in or for global health.

The boundaries around what constitutes 'global health research' are certainly blurry. For example, $\mathrm{PhD}$ candidates might wonder whether they are doing a thesis on global health if they are studying preclinical models of malaria transmission in a Japanese laboratory, or if they are studying the social determinants of Alzheimer's disease in the Democratic Republic of Congo, or conducting a systematic review on COVID-19 screening practices in airports throughout the world, or perhaps a clinical trial on a new intervention to improve the survival of preterm babies in three countries across South-East Asia, or studying how the global scientific publishing industry limits knowledge circulation in Africa.

Which ones fall within the definition of global health research? According to broad definitions, such as the one by Koplan et al or by Salm et al, it may be hard to know. But a clearer definition of global health research would be useful, given that we have now created global health research structures that need to decide on strategy, content, priorities and action. The answer to these questions would help to prioritise the content of masters or $\mathrm{PhD}$ programmes in global health, the scope of departments that make up a global health institute, positions in academia and the focus of research calls or global health journals, among others. Having a clearer sense of the 'what' (the overall purpose/goal of research), the 'where' (the context in which the research is designed, conducted and used) and the 'who' (the 
people designing, conducting and using knowledge from research) of global health research would be desirable, if we are to have a more useful sense of what global health research means.

On the 'what': the quest for equity in health within nations and among nations should be what drives research efforts in global health. The structural determinants of health underpin disparities in health worldwide-whether between or within nations. ${ }^{8}$ The structural determinants of health should be a most important priority - why some people are more or less privileged and how to undo such disparities by resetting and unsettling entrenched systems. In fact by eliminating poverty, even without novel interventions, the global burden of many diseases would be reduced. ${ }^{9}$ Likewise, research on diseases and conditions affecting disproportionally the poor, driving the health and social development of many countries due to its perpetuating effect on poverty, need to be a priority in global health research.

While most diseases of poverty may not be of major concern for most people living in high-income countries,${ }^{10}$ they are for marginalised groups there (eg, Indigenous people, migrants, prisoners or racial, ethnic and sexual minorities) for whom the structural determinants of health (or poverty) are so rigged they experience a greater burden of such diseases than other groups. Thus, studies on how to change those structures, get the right interventions in place (or understand why they are not in place) and strengthen health systems (in high-income, middle-income or low-income countries) must be a top priority for global health research. Hence, on 'where'the location in which a study is conducted (or that the issues it addresses are transnational) - might not be what determines that it is global health research, but if the research speaks directly or ultimately to equity breaches.

What this means is that global health research does not take place only in low-income and middle-income countries. ${ }^{11}$ It is about inequities in health and the structures that create ill health for some and not for others. Those structures manifest through social, historical and political processes that make some locations 'low-resource settings'. In another recent paper in BMJ Global Health, van $\mathrm{Zyl}$ et al invite us to think more clearly about what we mean when we say 'low-resource settings' in global health research and practice. ${ }^{12}$ They argue that the assumption that 'low-resource settings' translates, if loosely, to the same thing as 'low-income and middle-income countries' can limit the transfer of knowledge and insight between low-resource settings in high-income countries and lowresource settings in low-income and middle-income countries.

Notably, van Zyl et al argue that instead of umbrella terms and framings such as low-resource setting or high-income, middle-income and low-income countries, researchers and commentators should be specific about why and how a setting is low-resource and along which dimension. While acknowledging that each lowresource setting is complex and low-resource in its own way, van Zyl and et al identified, in a review of the literature, dimensions of being a low-resource setting that may help us to be much more specific, nuanced and transparent about the 'where' of global health research. They include: (1) financial shortages, (2) suboptimal service delivery, (3) underdeveloped physical infrastructure, (4) underdeveloped knowledge infrastructure, (5) historical and sociocultural underpinnings, (6) geographical and environmental limitations and (7) human resource limitations. ${ }^{12}$

The 'where' and the 'what' of global health research has always followed the 'who'. The framing and term 'global health' itself emerged from high-income countries and has especially been dominated by researchers with a biomedical background in a way that has and continues to limit the extent to which people elsewhere and with diverse viewpoints and areas of focus can own the field. The framing of global health has consistently privileged diseases over systems, the status quo over emancipatory structural change, a quest for novel universal truths over locally useful knowledge, and research from a distant or foreign pose over deep proximate engagement from a local pose, addressing itself, by default, to a foreign gaze. $^{13}$

Clarity on what constitutes global health research begins with clarity on who defines global health research. The 'who' has so far determined the 'what' and 'where'. The 'who'-whether as those who frame the question, conduct the research, circulate the findings or constitute its audience-is essential for achieving greater clarity on the meaning of global health research. The 'who' has a direct bearing on whether global health research can advance equity. There are ethics and justice dimensions to the 'who'-what the 'who' can see, what their interests are, what perspectives they prioritise. In the quest for equity, the local and emancipatory 'who' are far more important than the foreign and technical 'who'.

People who are members of population groups or are based in regions which are disproportionally affected by the burden of ill health are critical actors to better define and interpret global health research, since they experience the largest equity gaps first-hand. ${ }^{14}$ Only in this way can we abandon colonial research practises which are unethical, unjust and prone to study design flaws or bias in interpretation. The field of global health research has been led by high-income country researchers conducting studies in low-income and middle-income countries, often analysing data/samples back in high-income countries and publishing their findings for high-income country audiences. ${ }^{15}$ Working towards equity in health should come with shifting these default settings.

With the 'what', 'where' and 'who' we have proposed, it is clear that global health research transcends the field of health, as the strategies for achieving equity require multisectoral and transdisciplinary perspectives. ${ }^{16} \quad 17$ However, current research funding and academic journal priorities encourage and incentivise single-discipline, single problem, disease-focussed, technocratic solutions, 
with knowledge produced for the foreign gaze. ${ }^{18}$ But it does not have to remain this way. With a new 'who', global health research can respond to growing calls to decolonise the field and even out the playing field among actors from different settings. ${ }^{19}$ It is time to experiment with new platforms that transcend the current anachronistic default in which publication in academic journals is seen as the primary mode of scientific communication and knowledge circulation. The internet and associated technologies provide virtual and other common spaces, which can help to democratise and decentralise knowledge systems-for research training, research dissemination and other knowledge-sharing purposes.

In conclusion, rather than proposing yet another definition of global health research, we highlight elements that we believe contribute to shape what we might see as global health research, its schemes and its core attributes. Achieving equity in health for all should be the driving force of global health research and education, ${ }^{20}$ wherever in the world that may be, nationally or transnationally. If all countries had a similar life expectancy, with equity within each country, the term 'global health research' would be redundant. Unfortunately, we are far from that scenario. The word 'global' itself in 'global health research' may be redundant already, given the risk of equating global health problems to transnational health problems. Perhaps 'global health research' should simply be called 'health equity research'.

Twitter Alberto L Garcia-Basteiro @agbasteiro and Seye Abimbola @seyeabimbola

Contributors Both authors have contributed equally to the manuscript.

Funding The authors have not declared a specific grant for this research from any funding agency in the public, commercial or not-for-profit sectors.

Competing interests ALG-B is associate editor of BMJ Global Health. SA is editor in chief of BMJ Global Health. There are no other conflicts of interest.

Patient consent for publication Not applicable.

Ethics approval This study does not involve human participants.

Provenance and peer review Not commissioned; internally peer reviewed.

Data availability statement There are no data in this work.

Open access This is an open access article distributed in accordance with the Creative Commons Attribution Non Commercial (CC BY-NC 4.0) license, which permits others to distribute, remix, adapt, build upon this work non-commercially, and license their derivative works on different terms, provided the original work is properly cited, appropriate credit is given, any changes made indicated, and the use is non-commercial. See: http://creativecommons.org/licenses/by-nc/4.0/.

\section{ORCID iDs}

Alberto L Garcia-Basteiro http://orcid.org/0000-0002-2038-5505

Seye Abimbola http://orcid.org/0000-0003-1294-3850

\section{REFERENCES}

1 Chen X. Understanding the development and perception of global health for more effective student education. Yale J Biol Med 2014:87:231-40.

2 Koplan JP, Bond TC, Merson MH, et al. Towards a common definition of global health. Lancet 2009;373:1993-5.

3 Fried LP, Bentley ME, Buekens P, et al. Global health is public health. Lancet 2010;375:535-7.

4 King NB, Koski A. Defining global health as public health somewhere else. BMJ Glob Health 2020;5:e002172.

5 Abimbola S. On the meaning of global health and the role of global health journals. Int Health 2018;10:63-5.

6 Turcotte-Tremblay A-M, Fregonese F, Kadio K, et al. Global health is more than just 'Public Health Somewhere Else'. BMJ Glob Health 2020;5:e002545.

7 Salm M, Ali M, Minihane M, et al. Defining global health: findings from a systematic review and thematic analysis of the literature. $B M J$ Glob Health 2021;6:e005292.

8 Marmot M. Epidemiology of socioeconomic status and health: are determinants within countries the same as between countries? Ann NY Acad Sci 1999;896:16-29.

9 Carter DJ, Glaziou P, Lönnroth K, et al. The impact of social protection and poverty elimination on global tuberculosis incidence: a statistical modelling analysis of sustainable development goal 1 . Lancet Glob Health 2018;6:e514-22.

10 Institute for Health Metrics and Evaluation. GBD results tool. Available: http://ghdx.healthdata.org/gbd-results-tool [Accessed 28 Aug 2018].

11 Herzig van Wees S, Holmer H. Global health beyond geographical boundaries: reflections from global health education. BMJ Glob Health 2020:5:2583:e002583.

12 van Zyl C, Badenhorst M, Hanekom S, et al. Unravelling 'lowresource settings': a systematic scoping review with qualitative content analysis. BMJ Glob Health 2021;6:e005190.

13 Abimbola $\mathrm{S}$. The uses of knowledge in global health. BMJ Glob Health 2021;6:e005802.

14 Bhakuni $\mathrm{H}$, Abimbola S. Epistemic injustice in academic global health. Lancet Glob Health 2021;9:e1465-70.

15 Hedt-Gauthier BL, Jeufack HM, Neufeld NH, et al. Stuck in the middle: a systematic review of authorship in collaborative health research in Africa, 2014-2016. BMJ Glob Health 2019;4:e001853.

16 Picard M, Sabiston CM, McNamara JK. The need for a transdisciplinary, global health framework. J Altern Complement Med 2011;17:179-84.

17 Masunaga Y, Jaiteh F, Manneh E, et al. The community lab of ideas for health: community-based Transdisciplinary solutions in a malaria elimination trial in the Gambia. Front Public Health 2021;9.

18 Abimbola S. The foreign gaze: authorship in academic global health. BMJ Glob Health 2019;4:e002068.

19 Abimbola S, Pai M. Will global health survive its decolonisation? Lancet 2020;396:1627-8.

20 Adams LV, Wagner CM, Nutt CT, et al. The future of global health education: training for equity in global health. BMC Med Educ 2016;16:1-7. 